\title{
TRADUÇÃO, DIÁLOGO, TESTEMUNHO: PRIMO LEVI E SEUS TRADUTORES
}

\author{
Anna Basevi ${ }^{1}$ \\ -1Universidade Estadual do Rio de Janeiro, Rio de Janeiro, Brasil
}

\begin{abstract}
Resumo: A aventura das numerosas traduções de textos do escritor italiano Primo Levi (1919-1987), sobrevivente de Auschwitz, mas também reconhecido como um grande narrador do século XX, aponta para a importância de uma leitura atenta, competente das questões testemunhais e literárias, capaz de se colocar numa dimensão relacional. Se o ato tradutório pode ser abordado como relação entre textos (Meschonnic) - e não apenas entre línguas -, a solução de impasses ou o enriquecimento que advém da soma do original com seu texto traduzido pode se dar também graças a relações pessoais e de intensa escuta entre escritor e tradutor, ou, se quisermos usar uma expressão ao mesmo tempo química e literária, graças às afinidades eletivas instauradas na leitura (e releitura operada por ambos). Interessantes casos das traduções inglesa e alemã do primeiro texto de Levi, Se questo è un uomo (1947/ 2 ed.1958), serão relatados para compor um quadro panorâmico de sucessos e problemáticas, mas também para introduzir a questão específica da tradução brasileira do livro (editora Rocco, 1988), seus limites e potenciais desafios futuros.
\end{abstract}

Palavras-chave: Literatura de Testemunho; Primo Levi; Tradução

\section{TRANSLATION, DIALOGUE, TESTIMONY: PRIMO LEVI AND HIS TRANSLATORS}

\begin{abstract}
The adventure of the numerous translations of Primo Levi (1919-1987) first book - the autobiography about Auschwitz experience, but also recognized as a great literary work of the twentieth century -, points to the importance of careful, competent reading of witness and literary questions, and able to place itself in a relational dimension. If the
\end{abstract}


translation act can be approached as a relation between texts (Meschonnic) - and not just between languages - the solution of impasses, or the enrichment that comes from the sum of the original with its translated text, can also happen thanks to personal and intense thanks to personal relationships and intense listening between writer and translator.If we want to use both a chemical and literary expression, we can say that it happens thanks to the elective affinities established in reading (and rereading operated by both). Interesting cases of the English and German translations of Levi's first text, Se questo è un uomo (1947/ 2 ed.1958) will be reported to compose a panoramic picture of successes and problems, but also to introduce the specific issue of the book's Brazilian translation (ed. Rocco, 1988), its limits and potential future challenges.

Keywords: Primo Levi; Testimonial Literature; Translation

\section{A tradução como extensão do testemunho ${ }^{1}$}

Diante da intenção dos nazistas de destruir as provas de seus crimes, surgiu o problema de como garantir a sobrevivência do testemunho, trasformando-o de oculto a dito ou escrito. Tal transmissão pós-catástrofe é um ato de traslatio, afirma Lina Insana, meditado durante o período do campo, como preparação para o depois. Neste sentido, a testemunha é já um tradutor. Um paralelismo estreito entre dificuldades do testemunho e da tradução é traçado pela autora em Ardous tasks. Primo Levi, translation and the transmission of holocaust testimony. Sabemos como a urgência de relatar os campos de extermínio se deparou com um muro de indiferença que durou pelo menos duas décadas (até uma sequência de contextos sócio-históricos que despertaram o interesse pelas testemunhas) e induziu muitos sobreviventes ao silêncio, uma reação pós-traumática, esta, já muito frequente neste tipo de situações.

O objetivo da junção testemunho-tradução, porém, estende-se para mais longe: "to show that Levi's attempts to meet the challenges of [...] the survival - in the belief that effective communication was fundamental to the human condition - are informed by the

${ }^{1}$ (Insana, 198).

Cad. Trad., Florianópolis, v. 40, no 3, p. 75-91, set-dez, 2020. 
concerns, challenges, figures - and indeed acts - of translation" (Insana, 4). A proposta consiste em mostrar o quanto a metáfora da tradução seja particularmente apropriada para o estudo da obra de Levi, não apenas por causa do trabalho realizado como tradutor, mas também pela atenção dedicada às questões de linguagem, códigos, sistemas de escrita. Sabemos que em É isto um homem? (Se questo è un uomo) a tradução torna-se logo a forma verbal cotidiana que permite a sobrevivência do italiano Levi. E, para resistir entre as infinitas e absurdas restrições pré-fixadas do Campo, a língua alemã se torna necessária como um complexo know-how do comunicar e de truques, a fim de saber exatamente onde ir, a quem pedir, o que dizer, o que não dizer. O sobrevivente, portanto, já permaneceu imerso na incomunicabilidade e dela saiu. O passo seguinte para a testemunha seria traduzir sua experiência numa narração ou relato capaz de gerar uma transmissão real para o leitor ou quem escuta. Todavia, é preciso que este público sinta a responsabilidade da escuta como parte da realização do testemunho. Como escreveu Jeanne Marie Gagnebin ((a), 57), "testemunha é também aquele que não vai embora, que consegue ouvir a narração insuportável do outro e que aceita que suas palavras levem adiante, como num revezamento, a história do outro". E assim como o leitor, podemos afirmar que o tradutor se configura como um ouvinte privilegiado investido de uma igualmente urgente responsabilidade testemunhal. Por esta razão, investigar as linhas tradutórias concretas e possíveis da literatura testemunhal abre o debate sobre aspectos desta escuta que, por ser ética, deve levar em conta o estilo do testemunho.

A história da primeira edição de Se questo è un uomo revela uma lacuna de escuta e acolhimento, não raros naqueles anos de pós-guerra, nos quais prevaleciam - pelo menos na Itália - a valorização dos combatentes da Resistência, o esquecimento institucional das responsabilidades fascistas e o foco na reconstrução, ignorando os traumas vividos pelas vítimas das deportações.

Em 1947, portanto, o livro não obteve grande circulação, pois fora recusado pela importante editora Einaudi, núcleo central dos 
intelectuais e escritores antifascistas da época, e foi publicado em poucas cópias por uma editora menor, a Francesco De Silva. Alguns anos depois, surgiu a possibilidade de supervisionar as traduções nas línguas conhecidas pelo escritor. Além do francês ${ }^{2}$, o inglês e o alemão. Estas traduções aconteceram logo na primeira década após a escrita da obra, antes mesmo do reconhecimento definitivo na Itália e Europa a partir de 1963 (ano de publicação do segundo livro La tregua) e na década de 80 nos EUA - graças ao sucesso de Il sistema periódico -, até ser traduzida em mais de 40 línguas.

\section{Da primeira tradução à obra completa traduzida}

A tradução inglesa foi a primeira. Stuart Woolf, jovem de Oxford, de origens judaicas e estudante de literatura, chegou em Turim em 1956 e conheceu o texto de $\mathrm{SQU}^{3}$ em sua primeira edição (a segunda e mais afortunada edição será publicada em 1958 pela própria Einaudi). Logo decidiu que precisaria traduzi-lo. Quando procurou Primo Levi, este acolheu a oportunidade de um estreito contato com o tradutor. Durante um ano, duas vezes por semana, o químico Levi e o pesquisador de história Woolf se encontravam depois dos recíprocos trabalhos. Woolf admite não ter tido nenhum conhecimento teórico sobre tradução, em uma época na qual a especialização não havia alcançado o estatuto de hoje. Embora também não tivesse muito conhecimento de literatura, no entanto a prática empírica feita de debate e diálogo entre escritor

${ }^{2}$ No que diz respeito à tradução francesa, segundo Levi, suas graves lacunas foram responsáveis do escasso sucesso do livro na França em 1961. Naquela ocasião, o escritor não fora convocado em nenhum momento e, portanto, não houve troca com o tradutor nem com a editora. Por esta razão, mais tarde, graças à correspondência com uma estudiosa francesa Levi desejou que ela fosse sua tradutora em francês para poder repetir o diálogo tradutor-escritor. Embora isso não tenha se realizado, uma nova tradução francesa mais atenciosa foi publicada em 1987, ano da morte do escritor.

${ }^{3}$ SQU indica a obra original Se questo è un uomo, segundo a convenção existente entre os críticos italianos. 
e tradutor permitiu a realização do projeto e, em 1959, o livro foi publicado nos EUA e em seguida na Inglaterra, com grandes elogios da crítica, tanto ao escritor como ao tradutor. Quando alguns anos depois, traduziu La tregua (The truce), Woolf recebeu um prêmio pela British Italian Society. Ainda assim, os muitos elogios de críticos não foram suficientes para o sucesso dos dois livros no mundo anglo-saxão: este chegará bem mais tarde, em 1984, nos EUA, com a publicação de Il sistema periodico (The periodic table). A dificuldade de escuta e de leitura por um vasto público era devida às mesmas razões que adiaram o êxito na Itália (questões psicossociais e históricas), somadas à sensação, por parte da população inglesa, de uma experiência externa. Não apenas porque dizia respeito à perseguição dos judeus, mas também pela maior distância em relação à vivência da ocupação nazista.

No entanto, o título proposto para a primeira edição de $S Q U$ nos EUA havia sido Survival in Auschwitz, enquanto em Londres constava o título If this is a man. Em 1961, em Nova York, determinou-se, portanto, uma fórmula mais comercial com o nome de Auschwitz em destaque e o termo "survival" visando sugerir uma espécie de happy end, como observa Domenico Scarpa (95). O crítico sublinha o equívoco que se cria, na versão americana, em torno da vida individual de um sobrevivente (e ainda mais um sobrevivente italiano, isto é, hábil e esperto, segundo o estereótipo, da arte de "se virar") ofuscando a dimensão coletiva sugerida pela palavra "uото" (man), desencadeadora de importantes interrogações sobre a humanidade e o humano. Em suma, uma "idéia banal que levou a mudar o título de uma obra excepcional" (Ibidem).

Hoje, nos EUA a obra completa foi retraduzida pela editora Liveright, com a tradução de Se questo è un uomo revisada pelo próprio Stuart Woolf enquanto a de $A$ trégua foi atualizada por Ann Goldstein, tradutora também do restante da obra. Goldstein (10-13) orientou-se segundo princípios de "fidelidade" ao estilo do autor, levando em consideração a precisão da escolha das palavras e sua estratificação semântica, e seguindo a ideia de manter um número similar de termos nas frases e nos parágrafos para acompanhar 
a economia expressiva. E, acima de tudo, preservando clareza e elegância da linguagem.

Scarpa - responsável pela supervisão italiana desta recente tradução norte-americana - destaca o quanto fosse importante "transplantar em outro lugar a obra de Levi com suas raízes" ou seja, manter tanto a peculiaridade de uma cultura de língua minoritária no interior de uma língua hegemônica, quanto o estilo específico de Levi, sua marca literária e humana. O resultado, segundo o crítico, seria uma tradução atenta e meticulosa (Scarpa, 143-145).

No ensaio In un 'altra lingua, Scarpa visa esclarecer que não existe a "tradução integral": trata-se de uma impossibilidade teórica à qual corresponde uma necessidade concreta. "Na teoria não é possível, no entanto, se faz, há de ser feito na prática: traduzir, testemunhar" (57). Scarpa define "radical" o "princípio de fidelidade literal a uma língua", onde a literalidade aproxima-se ao conceito que Berman desenvolve ao falar de uma relação criativa, mas atenta com a letra (Berman, 9-33) ${ }^{4}$. A proposta da nova tradução norte-americana consiste em conservar a coerência interna do autor e, com a fórmula "ler em italiano, copiar em inglês", Scarpa (55) sintetiza a intenção de manter aquele estranhamento presente ao ler a própria língua do interior da outra, sem associar a ideia do copiar à criação de algo idêntico. A tradução seria, pelo contrário, uma operação artesanal.

\section{O encontro esperado: a tradução alemã}

Todavia foi à tradução alemã que o escritor atribuiu a prioridade, pois era vital a comunicação com os alemães, primeiros destinatários do livro ${ }^{5}$. Quem são os alemães de Levi? Não apenas um

\footnotetext{
${ }^{4}$ A literalidade de Berman, ao se aproximar do significado textual, longe tanto do sentido literal quanto das tendências de etnocentrismo e domesticação, visa manter a estranheza do estrangeiro na tradução.

5 Aprofundamos aqui um aspecto acenado no artigo " $\mathrm{O}$ tradutor como testemunha”, publicado em Cadernos de tradução, v.38, n.3 (2018).
} 
grupo genérico de cidadãos de outro país, mas os que assistiram calados ou apavorados, os que contribuíram à máquina de exclusão ou até de aniquilação, os que aplaudiram Hitler ou simplesmente não fizeram nada. Entre os omissos, os coniventes e até mesmo os algozes procurou uma resposta com a urgência de um desejo intenso, uma necessidade de compreensão e ressarcimento moral ao mesmo tempo: "O encontro que eu esperava, e com o qual tão intensamente sonhava (em alemão) à noite, era um encontro com um daqueles de lá, que dispuseram de nós, que não nos olharam nos olhos, como se nós não tivéssemos olhos" (Levi (b), 214-215). $\mathrm{O}$ anseio do diálogo com o ex-inimigo possui vários desdobramentos, um dos quais se manifesta justamente na importância dada à tradução alemã de SQU.

O tradutor deveria ser o mais próximo possível à tipologia de alemão que se opôs ao nazismo, condição necessária à instauração tanto da confiança quanto de um testemunho por "procuração". A biografia de Riedt garantiu requisitos essenciais: a recusa de servir no exército, a deportação do sogro a Auschwitz, o estudo de literatura na Itália, a participação na Resistência armada italiana. Retornando à Alemanha oriental, ele ainda precisou fugir das perseguições ideológicas do regime e emigrar para a Alemanha ocidental.

Antes do trabalho de tradução começar, Levi pediu ao editor que lhe enviasse as páginas, à medida que eram traduzidas: "eu intimava-o a não cortar ou trocar uma só palavra do texto, e exigia mandar-me o original da tradução por partes, capítulo por capítulo, à medida que o trabalho prosseguisse; queria controlar sua fidelidade, não só lexical, mas interna" (Levi (c), 105). De fato as cartas resultam muito objetivas, mas cheias de cordialidade e admiração mútua embora num tom reservado.

O tradutor se depara com uma língua que às vezes não reconhece. Riedt oferece frequentemente duas possibilidades para a tradução de alguma palavra que ele percebe ser ligada ao contexto do Lager, e muitas vezes Levi insiste de fato em manter palavras que não funcionam bem no alemão comum, ou que o tradutor desconhece, mas que faziam parte do jargão ou da própria língua ídiche. A 
um certo ponto, Levi faz uma lista de palavras de jargão sugerindo a substituição dos termos inicialmente traduzidos em alemão polido.

$\mathrm{O}$ tradutor percebe que a experiência direta do campo de extermínio permite um conhecimento específico que nenhum tradutor teria e, assim, expressa sua dúvida numa carta: "como eram chamadas as seleções em alemão? É um problema sem solução para quem não tem experiência do Campo" (Levi; Riedt, 15). Além do léxico, a questão da "acústica" de um idioma nazificado e da Babel de Auschwitz permanecia essencial para Levi, como demonstra uma sua declaração: "queria que naquele livro, especialmente em sua versão alemã, não se perdesse nada das asperezas, das violências feitas à linguagem que, de resto, me esforçara ao máximo para reproduzir no original italiano" (Levi (c), 106) . A finalidade era restituir um alemão "que soasse ao ouvido deles como uma língua estrangeira" (ibid.), aquele mesmo estranhamento que os executivos da Bayer haviam sentido ao ouvir Levi se expressar com o jargão do campo num contexto formal de trabalho já distante da guerra. Traduzir SQU em alemão significava, portanto, "devolver a acústica de Auschwitz a seu lugar de origem" (Scarpa, 65). O leitor alemão havia de vivenciar a dissonância, o estranhamento sonoro de sua língua usada para a morte, a presença ainda viva da história recente, e esta sonoridade o lembraria de uma ameaça permanente (ibid. 77).

Scarpa identifica outro elemento desnorteante para o leitor alemão: a imposição de um idioma quase-igual. Lembrando que o quase-igual seria também o cidadão alemão-judeu, reproduzindo-se, desta forma, uma situação similar à do momento em que foi desencadeado o antissemitismo hitleriano, quando o que mais apavorava não era a diferença, e sim a semelhança entre o Judeu responsável do Mal e o cidadão comum. Por esta razão, o estudioso considera sagaz a intuição de colocar os alemães na frente de um "espelho acústico" (ibid.) que levaria a perceber a correspondência entre o alemão degradado de Ist das ein Mensch? e o contexto propício ao ódio antissemita.

Em uma das cartas, por exemplo, o tradutor procura confirmar se Levi teria decidido deliberadamente citar o "odiado slogan na- 
zista" referente ao "vínculo do sangue e do solo": die Verbundenheit mit Blut und Boden. A resposta do escritor revela que o uso de tal expressão foi pertinente: na iminência da derrota, mesmo no olhar dos prisioneiros políticos, ele percebeu uma fronteira, e a identidade nacional que unia naquele momento os derrotados. Trata-se de uma crítica, evidentemente, e de uma vontade de reunir todos os alemães numa imagem de nacionalismo naquele momento bastante desprezível.

No diálogo com seu tradutor, o escritor tem a oportunidade de explicar com maior precisão onde há citações literárias implícitas ou explícitas, como as de Dante, ou ainda o que significava uma expressão, um movimento, um gesto. Não deixa de expressar dúvidas sobre palavras, por exemplo sobre a tradução do verbo demolire, demolir, na frase: "Allora per la prima volta ci siamo accorti che la nostra lingua manca di parole per esprimere questa offesa, la demolizione di un uomo" 6 . "Não estou muito convencido de "vernichten' para demolir”, escreve Levi. “Demolir é uma ação lenta, metódica, gradativa, progressiva. Vernichten é imediata, instantânea como esmagar uma mosca" (Levi; Riedt, 30).

Em Os afogados e os sobreviventes, no capítulo "Cartas de alemães", onde relata a interação com os leitores, mas também parte da história da tradução alemã, Levi escreve:

Experimentara um embaraço confuso, uma repugnância, um bloqueio emotivo que cortava o fluxo das ideias e da escrita [...] Deveria dar mais ênfase, subir à tribuna; de testemunha tornar-me juiz, pregador; expor teorias e interpretações da história; separar os justos dos pecadores, da terceira pessoa passar à segunda. Tudo isso constituía uma série de tarefas que me ultrapassavam, tarefas que de bom grado devolveria a outros, talvez aos leitores mesmos, alemães ou não ( Levi (c),107).

\footnotetext{
${ }^{6}$ Em português: "Pela primeira vez, então, nos damos conta de que a nossa língua não tem palavras para expressar esta ofensa, a aniquilação de um homem"(Levi (a), 24).
} 
Os "alemães" representavam aquele "outro", estranho, em parte inimigo cujas atitudes o escritor sobrevivente desejava desvendar. Como introdução à versão alemã de SQU, Levi propôs a carta ao tradutor, inteiramente publicada no capítulo mencionado e na qual afirma: "Hoje, por seu intermédio, posso falar aos alemães, recordar-lhes o que fizeram e dizer-lhes: 'Estou vivo, e gostaria de compreendê-los para julgá-los'” (ibid.). Além do conjunto de emoções que transbordam da relação com o público alemão, consideramos curiosa a afirmação sobre passar da terceira à segunda pessoa, numa tradução em língua alemã. Em SQU, a segunda pessoa do diálogo é o leitor, enquanto os alemães (os nazistas, os inimigos) permanecem na terceira (eles, ele). Uma vez que leitor e alemão coincidem, segundo uma simplificação emocional, o autor percebe um estranhamento que acaba por curto-circuitar a relação com a escrita.

A necessidade do escritor de ver seu testemunho lido pelo povo alemão demonstrou-se tão urgente, a ponto de fazê-lo aceitar as condições de censura na Alemanha Oriental, seja em SQU, seja em La tregua (especialmente os cortes relativos às descrições dos soldados soviéticos e dos prisioneiros políticos em Auschwitz quando pouco enobrecedoras). Contudo, o projeto foi dispensado (Belpoliti, 99).

Partindo do desejo explícito de ter os alemães como público-alvo, podemos deduzir, portanto, um aspecto paradoxal: que Levi escreve seu primeiro livro como uma tradução não apenas da experiência, mas da linguagem do campo. Um texto traduzido para o alemão, onde o alemão opera como um segundo original, seu duplo, especular, mas não simétrico. Algo que na linguagem de Levi diríamos "quiral", pois a quiralidade é a propriedade de algumas moléculas iguais como duas mãos, mas que não é possível sobrepor (uma assimetria que caracteriza a matéria orgânica). É como se tivesse escrito o livro em italiano para que fosse traduzido em alemão. "De certo modo", explica Levi (c, 148), "não se tratava de uma tradução, mas, antes, de uma restauração: esta versão era, ou eu queria que fosse, uma restitutio in pristinum ${ }^{7}$ uma retrover-

${ }^{7}$ Em latim indica uma indenização por um dano. 
são para a língua na qual as coisas tinham ocorrido e às quais se referiam". A tensão italiano/alemão cria uma aporia que embaralha as identidades de língua original/língua de tradução e torna única e original (em duplo sentido) a tradução alemã. Por sua vez, SQU estaria escrito como tradução de um ideal, ou como a negativa da versão alemã. Portanto, Levi que evidentemente escreveu em italiano precisou realizar uma supervisão constante e extremamente estreita da fundamental versão alemã do livro, como se fosse uma segunda escritura. Por esta razão, a edição alemã é descrita como um filho crescido, isto é, a continuação da mesma obra. Levi escreve ao Heinz Riedt: "Como compreenderá, é o único livro que escrevi, e agora que acabamos de vertê-lo para o alemão, sinto-me como um pai cujo filho chegou à maioridade e vai embora, e dele não se pode mais ocupar" (Levi, (c), 148). O verbo italiano trapiantare (traduzido com o menos metafórico "verter") remete a um verdadeiro transplante num outro terreno da mesma criação-criatura. $\mathrm{O}$ fato de que a tradução alemã seja comparada a um filho maduro prova o quanto esta etapa marque a ultimação da escrita de SQU, seu completamento. Nada é mais pertinente do que a afirmação de Meschonnic (31): "traduire peut continuer le texte" .

\section{Aspectos da tradução brasileira: intertextualidade e jargão}

Entre várias questões da tradução brasileira de 1988, pela editora Rocco - nunca mais atualizada -, abordaremos aqui apenas as duas ou três mais significativas e deixaremos de lado outras, inclusive a tradução dos títulos Se questo è un uomo em É isto um homem? (e não "Se isto é um homem", usado na edição de Portugal) e I sommersi e $i$ salvati em Os afogados e os sobreviventes (e não "Os submersos e os salvos", usado porém fielmente como título de um capítulo do primeiro livro). Neste último caso, é importante frisar que a palavra "sommersi" vem do Inferno dantesco, texto literário com o qual Levi dialoga constantemente, citando-o implícita ou explicitamente. E, sobretudo, utilizando este imagi- 
nário coletivo, compartilhado como instrumento para transmitir melhor a descrição de um inferno moderno.

De fato, a imagem do fundo, que inúmeras vezes se repete em SQU, corresponde ao fundo do inferno dantesco (Segre, 65).

A lacuna na tradução se dá ao não perceber este fundamental intertexto e retirá-lo para substituir expressões idiomáticas da língua portuguesa. Apresentamos o exemplo a seguir (o sublinhado é nosso):

vagoni merci, chiusi dall'esterno, e dentro uomini donne bambini, compressi senza pietà, come merce di dozzina, in viaggio verso il nulla, in viaggio all'ingiù, verso il fondo. Questa volta dentro siamo noi (Levi (e), 10) .

A tradução brasileira:

vagões de carga, trancados por fora, e, dentro, homens, mulheres e crianças socados sem piedade, como mercadoria barata, a caminho do nada, morro abaixo, para o fundo (Levi (a), 15).

Evidentemente apresentam-se duas lacunas notáveis: 1 - a omissão da última frase, reveladora da questão "dentro" e "fora": "questa volta dentro siamo noi" e que representa a virada de um ponto de vista, antes externo de observador, agora envolvido em primeira pessoa na tragédia; 2- "all'ingiù", de cabeça para baixo, remete ao inferno dantesco, uma pirâmide revirada abaixo da terra, e ao mundo revirado como metáfora do Campo. Todavia o tradutor opta pela expressão "morro abaixo" criando a imagem de uma descida percorrida pelo trem e usando uma expressão da língua fora do contexto.

Problemas parecidos são levantados pela tradução de "Eccomi dunque sul fondo" com outra expressão idiomática do português 
“Aqui estou, então: no fundo do poço", (Levi (a), 35) apagando a recorrência do diálogo intertextual com Dante.

Um segundo aspecto a ser destacado, para refletir sobre a tradução de uma obra ao mesmo tempo literária e testemunhal, é a identificação da importância do jargão do Lager. O significativo organisieren não poderia desaparecer sem ocultar a originalidade de um termo que deveria, ao contrário, pertencer a um vocabulário compartilhado entre escritor e leitor, correspondendo a uma nova leitura ampliada do evento Shoá. No entanto, encontramos tanto em $E$ isto um homem? quanto na edição brasileira dos contos a perda desta expressão típica do jargão do Lager, que é o verbo alemão organisieren, repetidamente usado por Levi em italiano (organizzare) para indicar ao mesmo tempo "arranjar", "encontrar", "roubar". Portanto, acreditamos que se deva traduzir tanto o verbo como seus derivados sempre com o campo semântico do português "organizar". A expressão com seus derivados possuía no Terceiro Reich uma densidade semântica, que não passou despercebida ao estudo atencioso do filólogo alemão Victor Klemperer: ele descreve seu uso por parte das autoridades nazistas e sua gradativa corrupção. "Organização" substitui aos poucos o conceito de "sistema", por ser a primeira palavra associada, segundo o filólogo, a algo de inconsciente, ou emocional, que se encontra no "centro da alma do povo germânico", enquanto um "sistema" evidencia o pensamento racional que o embasa e constrói (Klemperer, 132-133). Assim, a linguagem coloquial apodera-se do termo "organização" e ela começa a aparecer para designar a ideia de um trabalho bem feito, distribuído entre membros de um grupo por um "organizador". Numa segunda fase, por volta de 1943, a palavra "organizar" já "havia-se tornado ambígua" porque se aproximava a "trapacear", "enganar", "arranjar" (ibid. 134). E de fato, organisieren, na experiência de Levi e de todos os sobreviventes dos campos de extermínio, referia-se à "conquista" de objetos úteis ou comida: num ambiente onde era proibido possuir qualquer coisa, inclusive um fio de linha, tudo era fundamental. Uma casca de batata encontrada num lixo ou uma blusa tirada de um companheiro morto era algo 
“organizado". Organizar: o ato proibido porque imprescindível à sobrevivência. O verbo, porém, desaparece na tradução brasileira como termo do jargão: "Todos os detentores ilegais de segundas camisas, roubadas ou arranjadas ou até honestamente compradas em troca de pão" (Levi (a), 79). Compare-se com o original: "Tutti i detentori abusivi di seconde camicie, rubate od organizzate, o magari onestamente comperate con pane" (Levi (e), 97). Outro exemplo, entre muitos:

Da sei mesi dividevamo la cuccetta, e ogni grammo di cibo organizzato extra-razione (Levi (e), 195).

Fazia seis meses que compartilhávamos a cama e cada grama de comida extra que conseguíamos ((a) 157)

Através do verbo “organizar" é possível manter o múltiplo sentido do deslocamento de significados gerado pelo jargão do Lager numa das questões principais: a sobrevivência. Acreditamos que a expressão estimula algumas considerações, pois o fato do furto pertencer a uma ideia de "organização" reflete pelo menos três aspectos mais específicos: roubar faz parte das atividades consideradas pelas $S S$ ilegais, mas corriqueiras e vitais pelos prisioneiros. Portanto, roubar, encontrar, trocar tornam-se sinônimos do verbo organizar e também entre si; em segunda instância, o verbo evoca uma função humana e social, um quase-trabalho, o controle do habitat pelo ser humano; enfim, reflete, no nível dos prisioneiros, o valor que o Terceiro Reich dava ao espírito da organização, em todas suas formas. Nos primeiros dois casos, a linguagem eleva eticamente o sentido da ação, a qual é livrada do cunho negativo do furto. Em conclusão, consideramos importante apontar para a omissão semântica da tradução, pois o tema do jargão do Lager é de absoluta pregnância no texto de Levi, onde a precisão das palavras demonstra ser uma característica primordial do escritor. 
Mais uma anotação final. Entre as linhas tradutórias possíveis, gostaria de propor uma não tradução do termo Muselmann.

Por razões ainda não esclarecidas, os indivíduos que já demonstravam uma resignação fatal eram chamados, no jargão do Lager, $M u$ selmann, Muselmänner (literalmente "muçulmano, muçulmanos").

É evidente que hoje em dia o termo Muselmann, quando traduzido, carrega ambiguidades, neste nosso século, não mais aceitáveis.

Uma nota de Jeanne Marie Gagnebin na apresentação de $O$ que resta de Auschwitz de Giorgio Agamben ((b), 13) explicita e confirma o mal-estar relativamente à palavra, usada para indicar os "mortos-vivos": “A etimologia dessa expressão 'muçulmano' é obscura; da minha parte não consigo não ouvir, em todas as laboriosas explicações, como que uma certa desforra de caráter racista na boca das vítimas do antissemitismo". De fato, a não ser que seja usado pelos sobreviventes (que relatam uma linguagem ouvida e utilizada numa experiência concreta e autêntica), podemos, portanto, reafirmar o uso do termo alemão Muselmann, atrelado unicamente ao contexto do Campo, evitando o estranhamento dado por seu significado literal quando traduzido.

Todas as considerações até aqui feitas (e recuperando as observações sobre o traduzir e a escuta) nos conduziram ao questionamento de algumas traduções quando desatentas a um estilo "complexo e versátil, contudo, coerente" (Ferrero, 45). Não foi possível ilustrar todas as problemáticas, presentes em outros aspectos como os registros, os tempos verbais ou a peculiar pontuação. Todavia, tanto na relação escritor-tradutores quanto na breve análise de questões tradutórias, um tema se sobressai: a responsabilidade do tradutor no entendimento da relação com uma obra literária de testemunho e na assunção da precisão das palavras, a mesma que se apresenta como um traço característico do estilo do autor impulsionada pela urgência da tarefa testemunhal. 


\section{Referências}

Basevi, Anna. "O tradutor como testemunha.". Cadernos de Tradução. 38.3, (2018): 226-243. DOI: https://doi.org/10.5007/2175-7968.2018v38n3p226. Portal de Periódicos da UFSC. 20/01/2020. Disponível em: https://periodicos. ufsc.br/index.php/traducao/article/view/2175-7968.2018v38n3p226.

Belpoliti, Marco. Primo Levi, di fronte e di profilo. Milano: Guanda, 2015.

Berman, Antoine, A tradução e a letra ou o Albergue do longínquo. Tradução de Marie-Hélène Torres, Mauri Furlan e Andréia Guerini Florianópolis: PGET/ UFSC, 2013.

Ferrero, Ernesto. Primo Levi. La vita, le opere.Torino: Einaudi, 2007.

Gagnebin, Jeanne Marie (a). Lembrar, escrever, esquecer. SãoPaulo: Editora 34, 2006.

Gagnebin, Jeanne Marie (b). "Prefácio a Giorgio Agamben". O que resta de Auschwitz. Giorgio Agambem (Org). São Paulo: Boitempo editorial, 2008, pp.9-17.

Goldstein, Ann. "Quattro giovani soldati”, Ann Goldstein; Domenico Scarpa (Orgs.). In un 'altra lingua. (Lezione Primo Levi), Ann Goldstein; Domenico Scarpa (Orgs.). Torino: Einaudi, 2015, pp.3-36.

Insana, Lina N. Ardous tasks. Primo Levi, translation and the transmission of holocaust testimony. Toronto: University of Toronto Press Incorporated, 2009.

Klemperer, Victor. LTI. A língua do Terceiro Reich. Rio de Janeiro: Contraponto, 2009.

Levi, Primo (a). É isto um homem?.Tradução de Luigi Del Re. Rio de Janeiro: Rocco, 1988.

Levi, Primo (b). A tabela periódica. Tradução de Luis Sérgio Henriques. Rio de Janeiro: Relume-Dumará, 1994. 
Levi, Primo (c). Os afogados e os sobreviventes. Tradução de Luis Sérgio Henriques. São Paulo: Paz e terra, 2004.

Levi, Primo (d). 71 contos de Primo Levi. Tradução de Maurício Santana Dias. São Paulo: Companhia das Letras, 2005.

Levi, Primo (e). Se questo è un uomo. (Notas de Alberto Cavaglion).Torino: Einaudi, 2012.

Levi, Primo; Riedt, Heinz. Letters Primo Levi-Heinz Riedt. Ian Thomson collection, fasc.1406/2/22, Wiener Library, London.

Meschonnic, Henri. Poétique du traduire. Paris, Verdier, 1999.

Scarpa, Domenico. "Leggere in italiano, ricopiare in inglese." In un'altra lingua. (Lezione Primo Levi), Ann Goldstein; Domenico Scarpa (Orgs.). Torino: Einaudi, 2015, p.37-152.

Segre, Cesare. Lettura di "Se questo è un uomo", Primo Levi: Un'antologia della critica. Ferrero, Ernesto (Org.), Torino: Einaudi, 1997, p. 55-75.

Recebido em: 10/02/2020

Aceito em: 25/05/2020

Publicado em setembro de 2020

Anna Basevi. E-mail: annabasevi@hotmail.com. ORCID: https://orcid.org/00000002-6635-1239. Financiamento FAPERJ. 